\title{
Posttraumatic stress disorder and health functioning in a non-treatment- seeking sample of Iraq war veterans: A prospective analysis
}

\author{
Jennifer J. Vasterling, PhD; ${ }^{1-3 *}$ Jeremiah Schumm, PhD; ${ }^{4}$ Susan P. Proctor, DSc; ${ }^{5-6}$ Elisabeth Gentry; ${ }^{1,6}$ \\ Daniel W. King, PhD; ${ }^{1-3}$ Lynda A. King, PhD $^{1-3}$ \\ ${ }^{1}$ Department of Veterans Affairs (VA) Boston Healthcare System, Boston, MA; ${ }^{2}$ Boston University School of Medicine, \\ Boston, MA; ${ }^{3}$ VA National Center for Posttraumatic Stress Disorder, Boston, MA; ${ }^{4}$ Harvard Medical School at the VA \\ Boston Healthcare System, Boston, MA; ${ }^{5}$ U.S. Army Research Institute of Environmental Medicine, Natick, MA; \\ ${ }^{6}$ Boston University School of Public Health, Boston, MA
}

\begin{abstract}
To evaluate the impact of posttraumatic stress disorder (PTSD) on health-related functioning, we assessed 800 U.S. Army soldiers before and after 1-year military deployments to Iraq. As part of the Neurocognition Deployment Health Study procedures, each soldier completed at both time points self-report indexes of PTSD symptom severity, health behaviors (smoking, alcohol use), and somatic health-related functioning. Participants also completed a health-symptom checklist at the postdeployment assessment. Structural equation modeling revealed that postdeployment PTSD severity was associated with change in somatic health-related functioning, with postdeployment health symptoms as an intermediary variable. These relationships were independent of health risk behaviors, which had little association with somatic symptoms or PTSD. Our findings highlight the functional impact of PTSD, which extends beyond psychological symptoms to health-related daily functioning.
\end{abstract}

Key words: functioning, health, health risk behaviors, Iraq war, OIF, PTSD, rehabilitation, soldiers, veterans, VR-12.

\section{INTRODUCTION}

The clinical impact of posttraumatic stress disorder (PTSD) extends well beyond the more narrowly defined symptom criteria required by current diagnostic psychiatric taxonomy systems [1]. In addition to leading to a spectrum of psychological symptoms, PTSD is also associated with significant functional impairment, including increased risk of somatic symptoms and health disorders [2-7], health-related changes in day-to-day functioning [8-13], diminished overall well-being and quality of life [8,14-16], psychosocial and interpersonal dysfunction [17-19], and occupational impairment [17,20]. Such functional impairment, especially when health-related, may result in significant costs to society [13,21]. For example, individuals with a PTSD diagnosis use more medical services and incur higher healthcare costs than do individuals with other psychiatric disorders [7,16,21-27]. Among healthcare consumers, such as combat veterans,

\footnotetext{
Abbreviations: $\mathrm{AD}=$ active duty, $\mathrm{CFI}=$ comparative fit index, NDHS = Neurocognition Deployment Health Study, NG = National Guard, OIF = Operation Iraqi Freedom, PCL $=$ PTSD Checklist, PCS-12 = physical component summary (of Medical Outcomes Study 12-Item Short Form), PTSD = posttraumatic stress disorder, RMSEA = root-mean-square error of approximation, $\mathrm{SD}=$ standard deviation, SEM = structural equation modeling, SF-12 = (Medical Outcomes Study) 12-Item Short Form, VA $=$ Department of Veterans Affairs, VR-12 $=($ Medical Outcomes Study) 12-Item Short Form for military veterans.

*Address all correspondence to Jennifer $\mathbf{J}$. Vasterling, PhD; Psychology (116B), VA Boston Healthcare System, 150 South Huntington Avenue, Boston, MA 02130; 857-364-6522: fax: 857-364-4408. Email: jennifer.vasterling@va.gov

DOI: 10.1682/JRRD.2007.05.0077
} 
who are at increased risk for PTSD [28-31], the personal burden and societal costs may reach unacceptably high levels.

Although mounting empirical evidence strongly suggests that higher levels of PTSD are associated with poorer health-related functional outcomes, less is known about potential mechanisms leading to health-related dysfunction in PTSD [32]. Increased knowledge of the mechanisms (i.e., "mediators") through which PTSD leads to functional impairment may influence early interventions targeting prevention of health-related functional impairment. Likewise, identification of mediators potentially helps identify PTSD subsets at elevated risk, thereby informing resource allocation.

Health symptoms and health risk behaviors may be particularly important mediators of the relationship between PTSD symptomatology and health-related functional outcomes. PTSD has been linked both to increased risk of somatic symptoms such as dizziness, fainting spells, pounding or racing heart, or shortness of breath $[7,11,33-35]$ and to medical illnesses $[11,36]$ such as cardiovascular disease [29,37-38], nervous system disease [39], and gastrointestinal disorders [10]. Although several psychological [40-41] and biological [42-43] mechanisms may explain associations between PTSD and health outcomes [44], health risk behaviors such as alcohol use [5,45-46], tobacco use [5,9,47-48], and poor sleep hygiene $[7,43]$ stand out as potentially modifiable risk factors for poor health outcomes in individuals expressing high levels of PTSD symptoms [49]. Less is known, however, about the impact of PTSD-related health risk behaviors and health symptoms on health functioning.

Efforts to examine relationships between health risk behaviors or health symptoms and functional outcomes in PTSD identify both health behaviors and health symptoms as at least partially mediating the relationship between PTSD symptomatology and functioning, but these relationships remain inconclusive. For example, in comparison with population norms, a cohort of more than 800 military veterans seeking treatment for PTSD at a Department of Veterans Affairs (VA) facility showed increased health risk behaviors, increased chronic medical conditions, and poorer health-related functional outcomes [5]. Similarly, data from more than 36,000 respondents surveyed as part of the Canadian Community Health Survey indicated that PTSD was associated with physical health problems, poor quality of life, and short- and long-term disability [50]. Among more than 2,000 adults residing in New York City on the day of the World Trade Center attacks, excessive alcohol use was associated with both PTSD symptoms and poor mental health functional status [46].

In contrast, although alcohol use was high among patients who underwent surgery for physical traumas, it was not independently associated with functional outcomes; however, PTSD diagnosis predictably showed strong independent associations with functional outcomes [45], suggesting a direct link between PTSD and functioning. Results of the VA Normative Aging Study have suggested that PTSD is associated with functional outcomes independently of behaviors such as alcohol consumption and smoking [9], although links between smoking and functioning were also observed. Likewise, using cross-sectional data, Taft et al. found that PTSD symptom severity was the most important variable explaining functional health status among both men and women in a sample of more than 1,600 Vietnam veterans enrolled in the National Vietnam Veterans Readjustment Study [51]. Among male veterans, however, PTSD symptom severity was also linked to functional status via physical health conditions.

In one of the most comprehensive descriptions of causal pathways between PTSD symptoms and health functioning, Ford et al. studied more than 300 World War II veterans previously exposed to mustard gas [52]. This cross-sectional study revealed several important findings: (1) toxic exposure affected health problems and health functioning through PTSD symptoms (i.e., PTSD mediated the relationship between exposure and health), (2) although PTSD symptoms were directly related to health functioning, physical health problems also affected functional status and mediated the relationship between PTSD symptoms and healthcare use, and (3) alcohol use and smoking behaviors were not related to functional status or PTSD symptoms.

In this article, we have extended Ford et al.'s work [52] by addressing longitudinal relationships between PTSD symptomatology, health risk behaviors, health symptoms, and health-related functioning. Specifically, we examined the relationship of postdeployment PTSD symptom severity to pre- to postdeployment change in physical health-related functioning in U.S. Army soldiers deployed to Iraq in support of Operation Iraqi Freedom (OIF). Additionally, two health-related factors (i.e., health risk behaviors and health symptoms) were examined as 
potential mediators of this relationship. The prospective study design, including pre- and postdeployment assessments, offered a unique opportunity to examine directional relationships more rigorously than was possible within cross-sectional frameworks or via longitudinal assessment beginning after trauma exposure. The nontreatment-seeking sample of OIF veterans also provided a rare opportunity to examine relationships among PTSD symptoms, health risk behaviors, health symptoms, and health-related functioning in a recently trauma-exposed sample before development of chronic dysfunction.

We hypothesized that PTSD symptom severity at postdeployment would be inversely related to change in physical health functioning. Such change was measured with "residualized" scores: the values of the postdeployment functioning outcome measure after removing the contributions of the predeployment scores to this measure (i.e., a difference score between predicted physical health functioning from the earlier assessment and the actual observed score at the later assessment). We further predicted that in addition to direct relationships between PTSD symptomatology and physical health-related functioning, the relationship between PTSD symptoms and physical health-related functioning would be partially mediated by health-related risk behaviors and postdeployment health symptoms. In addition, we used our assessments of predeployment PTSD, smoking, and drinking and their associations with one another and with predeployment physical health functioning to examine the stability of the pattern of their relationships over time.

\section{METHODS}

\section{Human Subjects Considerations}

Human subjects approvals were obtained from the human subjects review boards of the Army, Tulane University Health Sciences Center (New Orleans, Louisiana), and VA. All participants provided written informed consent before participation.

\section{Participants}

Participants were 800 U.S. Army soldiers who deployed to Iraq in support of OIF between October 2003 and December 2004 and were assessed before (Time 1) and after (Time 2) their deployment. Participants were selected from a cohort of 1,542 soldiers enrolled in the Neurocognition Deployment Health Study (NDHS), a larger study targeting neuropsychological outcomes of Iraq deployment [53-54]. Detailed sampling, recruitment, and consent procedures are described elsewhere [54]. In brief, we conducted sampling at the battalion unit level and attempted to capture heterogeneous deployment experiences and geographic separation within the war zone. Units represented combat arms, combat support, and combat service support functions and were drawn from both the regular active duty (AD) force and the National Guard (NG). Study volunteers were not invited to complete procedures if they were pending separation from service or reassignment to another installation at Time 1 or if they were unable to complete the study protocol because of physical limitations (e.g., broken hand).

The Time 1 NDHS participation rate $(n=1,542)$ was high (94.4\%). At Time 2, participants who remained assigned to units located at the same AD military installation or NG armory were again invited to participate in the full study protocol. Of the 1,542 soldiers assessed at Time $1,75.5$ percent $(70.8 \%$ of soldiers from deployed units, $82.9 \%$ of soldiers from nondeployed units) participated at Time 2. Because our hypotheses centered on relationships between war-related PTSD and health functional impact, only soldiers who deployed between Time 1 and Time 2 are considered in this report. At Time 2, the predominant reason for nonparticipation among deployers was that they were no longer with their original military unit ( $n=$ 186, 60.4\%). Other reasons for nonparticipation at Time 2 included being on leave or special assignment $(n=36$, $11.7 \%$ ), being sick/injured ( $n=7,2.2 \%$ ), being deployed at Time $2(n=7,2.2 \%)$, declining participation $(n=7$, $2.2 \%)$, being a deactivated reservist $(n=4,1.3 \%)$, being deceased ( $n=3,1.0 \%)$, and other/unknown ( $n=58$, 18.8\%). An additional 24 deployers were excluded for invalid (i.e., internally inconsistent) questionnaire response profiles $(n=21)$ or not completing a questionnaire at both time points $(n=3)$, resulting in a final deployed sample of 800 (687 AD, 113 NG) soldiers.

At Time 1, participants in the final sample generally reflected the broader OIF-deployed Army population. On average (mean \pm standard deviation [SD]), participants were $25.8 \pm 6.0$ years of age, had completed $12.5 \pm$ 1.4 years of education, and had served in the Army $4.7 \pm$ 4.9 years. About one-half (46.9\%) were married at Time 1 , and about one-third (38.6\%) identified themselves as having ethnic minority status. Women $(7.0 \%)$ were underrepresented compared with the expected proportion of contemporaneously deployed Army women but were 
representative of the sex composition of participating military units. Commissioned officers (2.2\%) were also underrepresented. At Time 1, 11.5 percent had participated in a prior overseas operational deployment $(n=10$ deploying to Afghanistan or Kuwait in 2001 or later, $n=$ 1 participant having served in Iraq). The most prevalent military occupational categories were infantry/gun crew (37.0\%), communication/intelligence (16.5\%), electrical/ mechanical equipment repair (15.1\%), and service supply (8.1\%). Among participants for whom deployment and redeployment dates were available $(n=777)$, all but 27 (23 AD, 4 NG) served a 12-month OIF rotation.

\section{Measures}

Demographic (e.g., age, sex) and military (e.g., rank, deployment history) information was queried via interview and written survey questions. Military information was verified by service records. A comprehensive description of primary assessment data and secondary data obtained from automated military databases is provided elsewhere [52]. A description of the measures relevant to our hypotheses follows.

\section{Posttraumatic Stress Disorder Symptom Severity}

The PTSD Checklist (PCL), a widely used self-report scale measuring distress levels associated with each Diagnostic and Statistical Manual of Mental Disorders-Fourth Edition PTSD symptom [55], was used to derive PTSD symptom severity scores and was administered at Time 1 and Time 2. The civilian version was used for comparability across time points, including Time 1 in which the majority of participants had no prior combat exposure. The PCL is characterized by high test-retest reliability ( $r$ values $=0.92$ and 0.88 for immediate and 1-week retest, respectively), internal consistency (Cronbach $\alpha=$ 0.94 ), and convergent validity ( $r$ values $>0.75$ ) with other PTSD measures [56]. We generated dimensional symptom-based indicators of PTSD (i.e., reexperiencing, avoidance, emotional numbing, hyperarousal), reflecting a four-factor model [57], by grouping PCL items into appropriate subscale scores.

\footnotetext{
*Weathers FW, Litz BT, Herman DS, Huska JA, Keane TM. The PTSD Checklist: Reliability, validity, and diagnostic utility. In: Proceedings of the Annual Meeting of the International Society for Traumatic Stress Studies; 1993 Oct; San Antonio, Texas.
}

\section{Health Risk Behaviors and Health Symptoms}

To reduce respondent burden, we limited health risk behaviors to screening items judged to be of highest relevance to NDHS primary outcome domains (neuropsychological functions). Collected at Time 1 and Time 2, health risk measures included average number of alcoholic drinks a week in the month before assessment and current cigarette smoking. Smoking was categorized as either 0 (nonsmoking), 1 (less than one pack a day), 2 (one to two packs a day), or 3 (three or more packs a day) and then subsequently collapsed into 0 (nonsmoking) and 1 (smoking).

Health symptoms were measured at Time 2 with an abbreviated version of a health symptom checklist, adapted from earlier work involving 1991 gulf war veterans [58]. Each participant was asked to report the frequency with which he or she had experienced a set of 17 health symptoms and complaints (e.g., headaches, irregular heart beats, common cold) over the prior 30 days; frequency was measured on a scale from $0-4(0=$ no symptom; 1 = rarely, $1-2$ times in all; 2 = some, about once a week; 3 = often, several times a week; $4=$ very often, almost every day). We computed the summary score by summing the 17 symptom frequencies.

\section{Health-Related Functioning}

The self-appraised impact of somatic ("physical") problems on basic components of day-to-day functioning (e.g., accomplishing less than usual) was measured at Time 1 and Time 2 with the physical component summary (PCS-12) of the version of the Medical Outcomes Study 12-Item Short Form (SF-12) [59] that has been adapted for use in military veterans and designated the VR-12 (formerly the SF-12V). The VR-12 is the short form of the widely used SF-36V. PCS-12 component score have correlated highly with PCS-36 scores ( $r=$ 0.95) from the SF-36 (i.e., long form) [60]. Alternate forms reliability measures have shown estimates from 0.84 to 0.90 across different samples varied by age, sex, and health status [60]. Test-retest reliability, based on intraclass correlations, has been high for nondisabled community volunteers $(r=0.84)$ [61] and volunteers with severe mental illness diagnoses $(r=0.79)$ [62].

\section{Procedures}

As described by Vasterling et al. [54], survey measures were administered in small groups at military installations for most participants. We also contacted by mail a smaller subset of participants $(n=21)$ who were not present at 
military installations during Time 2 data collection. Time 1 assessments for deploying military units occurred between April 2003 and July 2004. Face-to-face Time 2 assessments occurred between January 2005 and September 2006, with mail assessments completed by December 2006.

Predeployment assessment of AD soldiers occurred $95.2 \pm 95.1$ days (mean \pm SD) before actual deployment (median $=45$ days), although most participants thought deployment to be imminent at the time of their assessments. The discrepancy between expected and actual deployment dates reflects that a subset of AD participants belonged to military units for which deployment orders were cancelled after their Time 1 assessment. Deployment orders for these units were subsequently reinstated. Thus, although all units were actively preparing to deploy at Time 1 , a subset did not actually deploy until several months later.

At Time 1, NG soldiers had been recently mobilized from their home states and sent to Camp Shelby (Mississippi) for training and preparation. The NG predeployment assessments immediately preceded participation in intensive desert training, which was followed by a brief return to Camp Shelby and then deployment to Iraq. Reflecting this sequence of events, predeployment assessment of NG soldiers occurred $114.3 \pm 31.9$ days (mean \pm SD) before their overseas deployment (median $=115$ days).

Postdeployment assessment of AD soldiers serving full tours occurred $73.4 \pm 19.5$ days (mean \pm SD) from each participant's return from Iraq (median $=75$ days); postdeployment assessment of NG soldiers occurred $197.5 \pm 34.0$ days after their return from Iraq (median = 189 days), reflecting scheduling constraints associated with the timing of NG postdeployment assemblies.

\section{Statistical Analyses}

\section{Data Preparation}

Missing values for specific items (occurring in $<3 \%$ of cases) were replaced by the mean value of the individual's completed items for that measure; however, if less than 50 percent of the items on a measure were completed, summary scores were not computed.

\section{Analyses}

For all analyses, raw data were submitted to the Mplus program, version 4.1 (Muthén \& Muthén, Los Angeles, California) [63]. Before computing the multi- variate models, we examined and interpreted an estimated bivariate correlation matrix of the latent study variables according to Cohen [64]. Structural equation modeling (SEM) was used to test the hypothesized models. Data were collected and therefore clustered within battalion-level units. To account for the effects of assignment to a particular battalion, we entered battalion unit membership as a cluster variable into all SEM equations. Age was included as a covariate in all SEM analyses. The full information maximum likelihood method was used to accommodate missing data (occurring in $14 \%$ of cases). Soldiers who did not participate in the postdeployment assessment were excluded from analyses.

PTSD was modeled as a latent variable with four observed indicators: PTSD reexperiencing, PTSD avoidance, PTSD numbing, and PTSD hyperarousal subscales. Age was included in the measurement model as an observed variable. The model also involved the following variables that were singly identified by their corresponding observed scale scores: predeployment smoking, predeployment drinking, predeployment physical functioning, postdeployment smoking, postdeployment drinking, postdeployment health symptoms, and postdeployment physical functioning.

SEM analyses followed a two-step approach. First, a measurement model was computed to test the adequacy of the hypothesized latent (i.e., not directly observed) variables in explaining the corresponding observed indicators. Second, a structural model was specified and evaluated to examine the effects of PTSD symptoms, negative health behaviors, and health symptoms on physical functioning. Variables from pre- and postdeployment time periods were used to test the hypothesized model pathways, with the exception of health symptoms, for which data were collected only at postdeployment. Mplus was used to calculate the direct and indirect effects of model predictors on physical functioning. The two-wave (pre- and postdeployment) data structure enabled us to examine whether model predictors influenced change in functioning over time and to ascertain the stability of predictors over the pre- to postdeployment interval.

All model variables were continuous with the exception of pre- and postdeployment smoking, which was modeled dichotomously (smoking vs nonsmoking). Mplus model pathways involving dichotomously modeled variables are based upon polychoric correlation coefficients [65]. Given that the smoking variable was dichotomous, the weighted least squares with mean and variance adjustment 
estimator, which has been shown to be an ideal estimator for models involving dichotomous data, ${ }^{*}$ was used in all SEM analyses.

\section{RESULTS}

\section{Variable Descriptives and Bivariate Correlations Among Study Variables}

Table 1 provides the mean and SD values of key study variables at pre- and postdeployment assessment. Results of bivariate correlational analyses revealed significant bivariate correlations in the hypothesized direction for most model latent variables (Table 2). Correlations between health risk behaviors (smoking and drinking) and other model variables were generally in the small range according to Cohen's guidelines [64]. The cross-sectional correlation between PTSD and physical functioning was small at predeployment and moderate at postdeployment. In contrast, postdeployment health symptoms evidenced a large correlation with postdeployment PTSD and a moderate to large correlation with postdeployment physical functioning. As would be expected, postdeployment values of key measures (PTSD, health behaviors, functioning) were strongly correlated with predeployment values of the same measures. This corre-

*Muthén B, du Toit SHC, Spisic D. Robust inference using weighted least squares and quadratic estimating equations in latent variable modeling with categorical and continuous outcomes. Unpublished manuscript, 1997. lation was particularly true of smoking status, which changed very little over time.

\section{Multivariate Structural Equation Modeling Analyses}

SEM was used to test the hypothesized multivariate model involving PTSD symptoms, health risk behaviors, health symptoms, and physical functioning at pre- and postdeployment (Figure 1).

\section{Measurement Model}

A measurement model was first calculated to determine the adequacy of the hypothesized latent model structure in explaining the underlying observed data. The measurement model was shown to produce an acceptable model fit. Although the chi-square test was significant $\left(\chi^{2}(5, N=800)=14.37, p=0.01\right)$, this test is shown to be extremely sensitive to even small model-data deviations with large samples and, thus, a poor measure of the overall statistical model [66]. Therefore, the comparative fit index (CFI) [67] and root-mean-square error of approximation (RMSEA) are more appropriate fit indexes by which to judge model fit. The CFI was 0.98 , exceeding the recommended standard of 0.95 , and the RMSEA estimate of 0.05 fell below its suggested maximum value of 0.08 [68-70]. These results suggested that the latent variable model effectively matched the underlying data structure.

\section{Structural Model}

A structural model was next computed to test the hypothesized relationships among study variables (Figure 1). Fit indexes for the structural model suggested an

Table 1.

Descriptive statistics (mean \pm standard deviation unless otherwise noted) of observed structural equation model variables for deployed soldiers who participated in predeployment (Time 1 ) and postdeployment (Time 2) assessments $(N=800)$.

\begin{tabular}{lcc}
\multicolumn{1}{c}{ Variable } & Time 1 & Time 2 \\
\hline PTSD Checklist Summary Score & & $9.38 \pm 4.43$ \\
Reexperiencing & $7.68 \pm 3.88$ & $3.85 \pm 2.17$ \\
Avoidance & $3.47 \pm 2.04$ & $8.46 \pm 4.05$ \\
Numbing & $8.13 \pm 3.85$ & $11.06 \pm 4.87$ \\
Hyperarousal & $9.32 \pm 4.16$ & $32.70 \pm 13.47$ \\
Summary & $28.60 \pm 12.04$ & 48.4 \\
Current Smoker (\%) & 48.9 & $8.29 \pm 10.61$ \\
Alcoholic Drinks per Week in Past Month & $7.51 \pm 11.52$ & $50.51 \pm 7.57$ \\
VR-12 Physical Component Score & $51.99 \pm 6.90$ & $13.40 \pm 11.59$ \\
Health Checklist Summary Score & - &
\end{tabular}

PTSD = posttraumatic stress disorder, VR-12 = Medical Outcomes Study 12-Item Short Form for military veterans. 
Table 2.

Estimated structural equation model latent variable correlations.

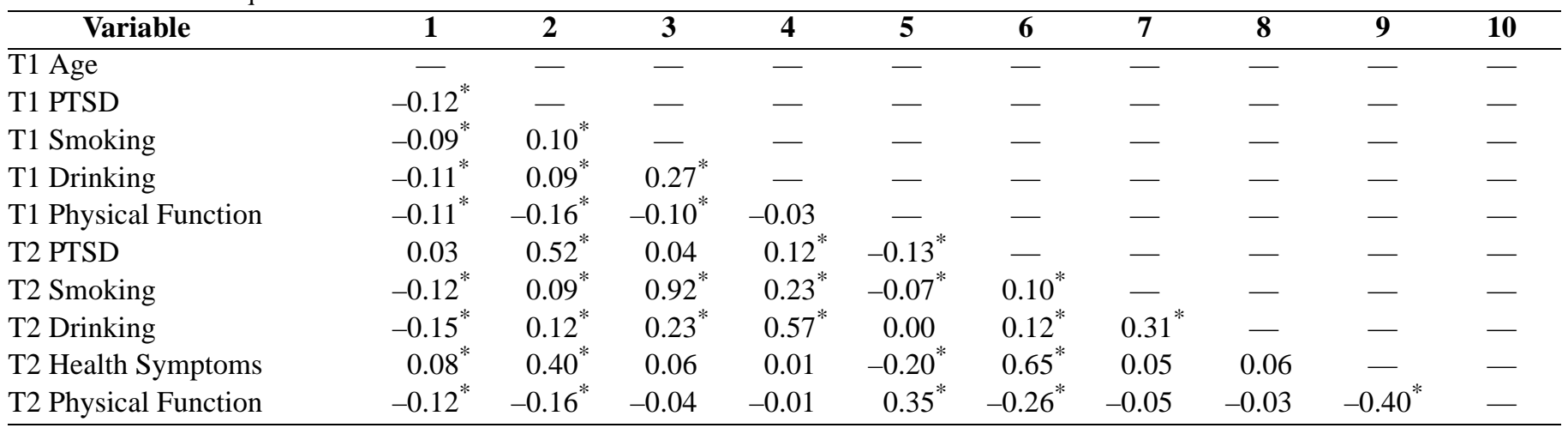

Note: Relationships involving smoking are based on polychoric correlations.

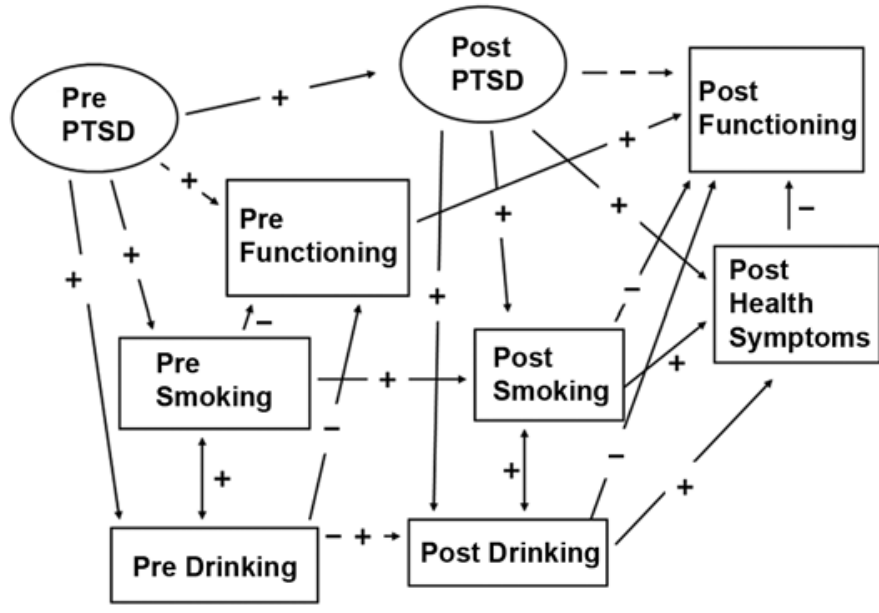

Figure 1.

Hypothesized structural model showing effects of posttraumatic stress disorder (PTSD) on health behaviors, health symptoms, and physical functioning (Functioning) at predeployment (Pre) and postdeployment (Post). Drinking = alcoholic drinks per week, Smoking: 0 = nonsmoking, $1=$ smoking.

acceptable fit to the data $\left(\chi^{2}(5, N=800)=16.53, p=\right.$ 0.006; CFI $=0.98$; $\mathrm{RMSEA}=0.05$ ).

\section{Predeployment}

At predeployment, more severe PTSD symptomatology was associated with greater alcohol consumption but the relationship between PTSD symptoms and smoking behaviors was nonsignificant (Figure 2). Endorsement of predeployment smoking was associated with poorer predeployment physical health functioning, whereas level of drinking was not related to physical functioning at the predeployment assessment. In addition, predeployment PTSD symptomatology was negatively associated with predeployment physical health functioning.

\section{Postdeployment}

At postdeployment, PTSD symptoms were again directly associated with drinking behavior. Moreover, this relationship was maintained even after controlling for predeployment drinking, suggesting that higher levels of postdeployment PTSD were associated with increased drinking from pre- to postdeployment. A large positive relationship was also observed between postdeployment PTSD and postdeployment health symptoms. In contrast to the direct relationship between PTSD symptoms and health functioning observed at predeployment, the association between postdeployment PTSD symptoms and change in physical health functioning across deployment was indirect (Figure 2). Specifically, the relationship between PTSD and functional change was almost entirely explained by postdeployment health symptoms (standardized indirect effects $=-0.27, p<0.001$ ). In the presence of PTSD, neither postdeployment drinking nor postdeployment smoking behaviors were associated with postdeployment health symptoms or physical health functioning (Table 3). Hence, changes in pre- to postdeployment physical health functioning were partially explained by the positive pathway from postdeployment PTSD to health symptoms and by the negative pathway from health symptoms to residualized change in physical health functioning. 


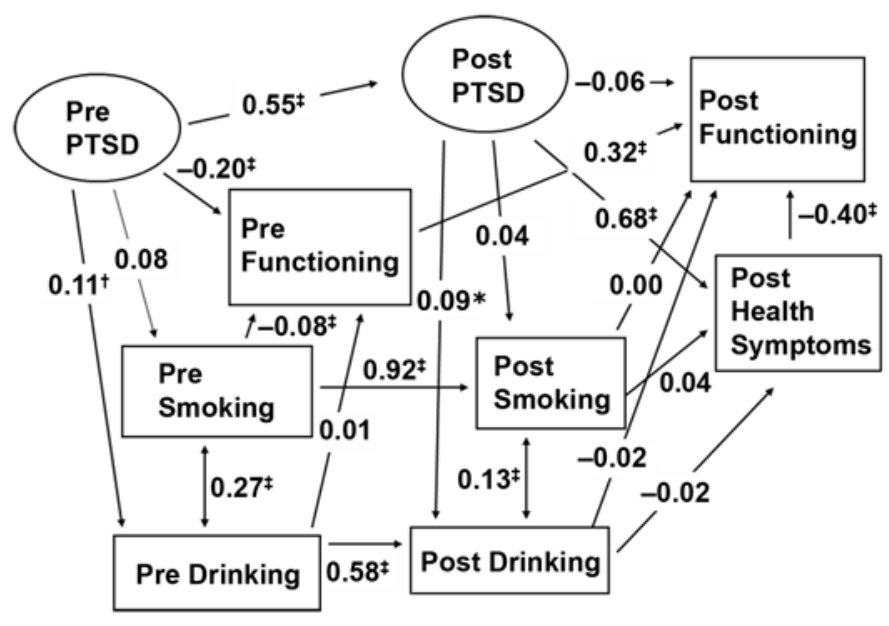

Figure 2.

Standardized structural model showing effects of posttraumatic stress disorder (PTSD) on health behaviors, health symptoms, and physical functioning (Functioning) at predeployment (Pre) and postdeployment (Post). ${ }^{*} p<0.05,{ }^{\dagger} p<0.01,{ }^{\ddagger} p<0.001$. All model variables were regressed on age. Following are significant standardized pathways from age: Pre Drinking $=-0.11$, Pre PTSD $=-0.12$, Pre Functioning $=-0.14$, Post PTSD $=0.09$, and Post Health Symptoms $=0.06$. Drinking $=$ alcoholic drinks per week, Smoking: 0 = nonsmoking, $1=$ smoking.

\section{DISCUSSION}

To our knowledge, this is the first study to examine longitudinal relationships between PTSD symptomatology and health-related functioning. In a sample of 800 U.S. Army soldiers deployed to Iraq, we found an indirect relationship between PTSD and health-related functional outcomes. Specifically, postdeployment PTSD symptom severity was only weakly related to day-to-day healthrelated functioning if the influence of health symptoms was controlled. Instead, PTSD symptoms seem to adversely impact physical health functioning via their negative effect on health symptoms, which in turn negatively influence day-to-day functioning. While it seems intuitive that the impact of health on day-to-day functioning has much to do with the number and frequency of somatic symptoms, particularly for military veterans and other trauma victims seeking treatment for PTSD, such health symptoms appear to be set in motion by PTSD.

Contrary to our hypotheses, the statistical model revealed no evidence that select health risk behaviors mediated PTSD symptoms and health symptoms. Although smoking mediated the relationship between PTSD and health functioning at predeployment, smoking was not related to either PTSD symptoms or health functioning at postdeployment. Instead, smoking status appeared to be relatively invariant across time, regardless of PTSD symptom levels or health functioning status. Therefore, neither the direct relationship between PTSD symptoms and health symptoms nor the indirect relationship between PTSD and decline in health functioning (mediated by health symptoms) could be explained by health risk behaviors.

This finding suggests a more direct relationship, or the existence of an unobserved mediating factor, between PTSD and health symptom development. Several alternate mechanisms, such as depression [71], coping behaviors [72], and biological resiliency factors [73], have been proposed but not tested within our model. Alternately, our measurement of behavioral health risk factors, which was limited to relatively course screening measures, may not have captured the most relevant dimensions of health risk behavior.

Also noteworthy is that relationships between PTSD symptoms, health symptoms, and day-to-day functioning were demonstrated in a cohort of nontreatment-seeking, predominantly young Army soldiers who had recently returned from overseas deployment. Such relationships could be hypothesized to be even more prominent among treatment-seeking military veterans or those beginning to express more chronic symptoms of PTSD. That PTSD

Table 3.

Structural equation model standardized effects of postdeployment model predictors on postdeployment physical health functioning while controlling for predeployment physical health functioning.

\begin{tabular}{lccc}
\hline \multicolumn{1}{c}{ Variable } & Direct Effects & Indirect Effects & Total Effects \\
\hline Postdeployment Smoking & 0.00 & -0.02 & -0.02 \\
Postdeployment Drinking & -0.02 & 0.01 & -0.01 \\
Postdeployment Posttraumatic Stress Disorder & 0.06 & $-0.28^{*}$ & $-0.22^{*}$ \\
Postdeployment Health Symptoms & $-0.40^{*}$ & - & $-0.40^{*}$ \\
${ }^{*} p<0.001$. & &
\end{tabular}


symptoms were already exerting some impact on healthrelated functioning in a population not otherwise at heightened risk for diminished health status also highlights the benefits of early mental and physical health screening in both primary care and mental health settings, even among seemingly healthy, newly returning veterans. Finally, these findings indicate the need for early mental health interventions to consider health symptoms and functional impact. Such outcomes as quality of life, psychosocial relationships, and occupational functioning are equally important as intervention targets to more traditional symptom relief.

Interpretation of our study findings is limited by several factors, including the failure to measure somatic health symptoms at predeployment assessment; the restriction of health risk assessment to screening measures; the underrepresentation of women, officers, and reservists in the sample; and the inclusion of only one service branch. Nonetheless, the prospective design, large sample size, range of military occupational specialties, and the sample's representativeness of the larger deployed Army population on other relevant dimensions allowed examination of relationships among PTSD symptoms, health, and functioning in a manner not previously possible.

\section{CONCLUSIONS}

This prospective study of a large cohort of U.S. Army soldiers who deployed to Iraq in support of OIF revealed that the impact of PTSD extends beyond adverse emotional sequelae to health symptoms and healthrelated day-to-day functioning. The findings have significant implications for the reduction of personal burden and societal costs among military veterans and other trauma-exposed populations who develop PTSD symptoms after exposure to extreme stress.

\section{ACKNOWLEDGMENTS}

We would like to thank the soldier participants and their sponsoring military units. We are also grateful to the Corp Surgeons' Offices that supported the study; the Office of the Command Surgeon, U.S. Army Forces Command; and the U.S. Army Research Institute of Environmental Medicine. The study could not have been conducted without the generosity of the largely volunteer examiner team. Finally, we thank Dr. Casey Taft for his review of an earlier version of the manuscript.

This material was based on work supported by the U.S. Army Medical Research and Materiel Command (grant DAMD 17-03-0020, HSRRB Log No. A-11815); VA Clinical Sciences Research and Development Awards; and the VA South Central Mental Illness Research, Education, and Clinical Center. Portions of this work were completed at the Southeast Louisiana Veterans Healthcare System (formerly the New Orleans VA Medical Center).

The opinions or assertions contained herein are the private views of the authors and not to be construed as official or reflecting the views of the U.S. Government. The investigators have adhered to the policies for protection of human subjects as prescribed in Army Regulation $70-25$, and the research was conducted in adherence with the provisions of 32 CFR Part 219. Human subjects participated in these studies after giving their free and informed voluntary consent. Investigators adhered to Army Regulation 70-25 and U.S. Army Medical Research and Materiel Command Regulation 70-25 on the use of volunteers in research.

The authors have declared that no competing interests exist.

\section{REFERENCES}

1. Wilson JP. PTSD and complex PTSD: Symptoms, syndromes, and diagnoses. In: Wilson JP, Keane TM, editors. Assessing psychological trauma and PTSD. 2nd ed. New York (NY): Guilford Press; 2004. p. 7-44.

2. Friedman MJ, Schnurr PP. The relationship between PTSD, trauma, and physical health. In: Friedman MJ, Charney DS, Deutch AY, editors. Neurobiological and clinical consequences of stress: From normal adaptation to post-traumatic stress disorder. 1st ed. Philadelphia (PA): Lippincott-Raven Publishers; 1995. p. 507-33.

3. Beckham JC, Moore SD, Feldman ME, Hertzberg MA, Kirby AC, Fairbank JA. Health status, somatization, and severity of posttraumatic stress disorder in Vietnam combat veterans with posttraumatic stress disorder. Am J Psychiatry. 1998;155(11):1565-69. [PMID: 9812119]

4. Schnurr PP, Jankowski MK. Physical health and posttraumatic stress disorder: Review and synthesis. Semin Clin Neuropsychiatry. 1999;4(4):295-304. [PMID: 10553035]

5. Buckley TC, Mozley SL, Bedard MA, Dewulf A, Greif J. Preventive health behaviors, health-risk behaviors, physical 
morbidity, and health-related role functioning impairment in veterans with post-traumatic stress disorder. Mil Med. 2004;169(7):536-40. [PMID: 15291186]

6. Green BL, Kimerling R. Trauma, posttraumatic stress disorder, and health status. In: Schnurr PP, Green BL, editors. Trauma and health: Physical health consequences of exposure to extreme stress. Washington (DC): American Psychological Association; 2004. p. 13-42.

7. Hoge CW, Terhakopian A, Castro CA, Messer SC, Engel CC. Association of posttraumatic stress disorder with somatic symptoms, health care visits, and absenteeism among Iraq war veterans. Am J Psychiatry. 2007;164(1): 150-53. [PMID: 17202557]

8. Zatzick DF, Marmar CR, Weiss DS, Browner WS, Metzler TJ, Golding JM, Stewart A, Schlenger WE, Wells KB. Posttraumatic stress disorder and functioning and quality of life outcomes in a nationally representative sample of male Vietnam veterans. Am J Psychiatry. 1997;154(12):1690-95. [PMID: 9396947]

9. Schnurr PP, Spiro A 3rd. Combat exposure, posttraumatic stress disorder symptoms, and health behaviors as predictors of self-reported physical health in older veterans. J Nerv Ment Dis. 1999;187(6):353-59. [PMID: 10379722]

10. Schnurr PP, Spiro A 3rd, Paris AH. Physician-diagnosed medical disorders in relation to PTSD symptoms in older male military veterans. Health Psychol. 2000;19(1):91-97. [PMID: 10711592]

11. Barrett DH, Doebbeling CC, Schwartz DA, Voelker MD, Falter KH, Woolson RF, Doebbeling BN. Posttraumatic stress disorder and self-reported physical health status among U.S. Military personnel serving during the Gulf War period: A population-based study. Psychosomatics. 2002; 43(3):195-205. [PMID: 12075034]

12. Zayfert C, Dums AR, Ferguson RJ, Hegel MT. Health functioning impairments associated with posttraumatic stress disorder, anxiety disorders, and depression. J Nerv Ment Dis. 2002;190(4):233-40. [PMID: 11960084]

13. Magruder KM, Frueh BC, Knapp RG, Johnson MR, Vaughan JA 3rd, Carson TC, Powell DA, Hebert R. PTSD symptoms, demographic characteristics, and functional status among veterans treated in VA primary care clinics. J Trauma Stress. 2004;17(4):293-301. [PMID: 15462536]

14. Mancino MJ, Pyne JM, Tripathi S, Constans J, Roca V, Freeman T. Quality-adjusted health status in veterans with posttraumatic stress disorder. J Nerv Ment Dis. 2006; 194(11):877-79. [PMID: 17102715]

15. Schnurr PP, Hayes AF, Lunney CA, McFall M, Uddo M. Longitudinal analysis of the relationship between symptoms and quality of life in veterans treated for posttraumatic stress disorder. J Consult Clin Psychol. 2006;74(4): 707-13. [PMID: 16881778]
16. Erbes C, Westermeyer J, Engdahl B, Johnsen E. Post-traumatic stress disorder and service utilization in a sample of service members from Iraq and Afghanistan. Mil Med. 2007;172(4):359-63. [PMID: 17484303]

17. Frueh BC, Turner SM, Beidel DC, Cahill SP. Assessment of social functioning in combat veterans with PTSD. Aggress Violent Behav. 2001;6(1):79-90.

18. Bolton D, Hill J, O’Ryan D, Udwin O, Boyle S, Yule W. Long-term effects of psychological trauma on psychosocial functioning. J Child Psychol Psychiatry. 2004;45(5):1007-14. [PMID: 15225342]

19. Seal KH, Bertenthal D, Miner CR, Sen S, Marmar C. Bringing the war back home: Mental health disorders among 103,788 U.S. veterans returning from Iraq and Afghanistan seen at Department of Veterans Affairs facilities. Arch Intern Med. 2007;167(5):476-82.

[PMID: 17353495]

20. Stein MB, Walker JR, Hazen AL, Forde DR. Full and partial posttraumatic stress disorder: Findings from a community survey. Am J Psychiatry. 1997;154(8):1114-19. [PMID: 9247398]

21. Greenberg PE, Sisitsky T, Kessler RC, Finkelstein SN, Berndt ER, Davidson JR, Ballenger JC, Fyer AJ. The economic burden of anxiety disorders in the 1990s. J Clin Psychiatry. 1999;60(7):427-35. [PMID: 10453795]

22. Solomon SD, Davidson JR. Trauma: Prevalence, impairment, service use, and cost. J Clin Psychiatry. 1997;58 Suppl 9:5-11. [PMID: 9329445]

23. Marshall RP, Jorm AF, Grayson DA, O’Toole BI. Posttraumatic stress disorder and other predictors of health care consumption by Vietnam veterans. Psychiatr Serv. 1998;49(12): 1609-11. [PMID: 9856625]

24. Kessler RC, Zhao S, Katz SJ, Kouzis AC, Frank RG, Edlund M, Leaf P. Past-year use of outpatient services for psychiatric problems in the National Comorbidity Survey. Am J Psychiatry. 1999;156(1):115-23. [PMID: 9892306]

25. Deykin EY, Keane TM, Kaloupek D, Fincke G, Rothendler J, Siegfried M, Creamer K. Posttraumatic stress disorder and the use of health services. Psychosom Med. 2001; 63(5):835-41. [PMID: 11573033]

26. Calhoun PS, Bosworth HB, Grambow SC, Dudley TK, Beckham JC. Medical service utilization by veterans seeking help for posttraumatic stress disorder. Am J Psychiatry. 2002;159(12):2081-86. [PMID: 12450960]

27. Walker EA, Katon W, Russo J, Ciechanowski P, Newman E, Wagner AW. Health care costs associated with posttraumatic stress disorder symptoms in women. Arch Gen Psychiatry. 2003;60(4):369-74. [PMID: 12695314]

28. Kulka RA, Schlenger WE, Fairbank JA, Hough RL, Jordan BK, Marmar CR, Weiss DS. Trauma and the Vietnam War generation: Report of findings from the National Vietnam 
Veterans Readjustment Study. New York (NY): Brunner/ Mazel; 1990.

29. Kang HK, Natelson BH, Mahan CM, Lee KY, Murphy FM. Post-traumatic stress disorder and chronic fatigue syndrome-like illness among Gulf War veterans: A populationbased survey of 30,000 veterans. Am J Epidemiol. 2003; 157(2):141-48. [PMID: 12522021]

30. Hoge CW, Castro CA, Messer SC, McGurk D, Cotting DI, Koffman RL. Combat duty in Iraq and Afghanistan, mental health problems, and barriers to care. N Engl J Med. 2004; 351(1):13-22. [PMID: 15229303]

31. Dohrenwend BP, Turner JB, Turse NA, Adams BG, Koenen KC, Marshall R. The psychological risks of Vietnam for U.S. veterans: A revisit with new data and methods. Science. 2006;313(5789):979-82. [PMID: 16917066$]$

32. Buckley TC, Green BL, Schnurr PP. Trauma, PTSD, and physical health: Clinical issues. In: Wilson JP, Keane TM, editors. Assessing psychological trauma and PTSD. 2nd ed. New York (NY): Guilford; 2004. p. 441-65.

33. Wolfe J, Proctor SP, Erickson DJ, Heeren T, Friedman MJ, Huang MT, Sutker PB, Vasterling JJ, White RF. Relationship of psychiatric status to Gulf War veterans' health problems. Psychosom Med. 1999;61(4):532-40. [PMID: 10443762]

34. Martin L, Rosen LN, Durand DB, Knudson KH, Stretch RH. Psychological and physical health effects of sexual assaults and nonsexual traumas among male and female United States Army soldiers. Behav Med. 2000;26(1):23-33. [PMID: 10971881]

35. McCarroll JE, Ursano RJ, Fullerton CS, Liu X, Lundy A. Somatic symptoms in Gulf War mortuary workers. Psychosom Med. 2002;64(1):29-33. [PMID: 11818583

36. Wagner AW, Wolfe J, Rotnitsky A, Proctor SP, Erickson DJ. An investigation of the impact of posttraumatic stress disorder on physical health. J Trauma Stress. 2000;13(1): 41-55. [PMID: 10761173]

37. Boscarino JA, Chang J. Electrocardiogram abnormalities among men with stress-related psychiatric disorders: Implications for coronary heart disease and clinical research. Ann Behav Med. 1999;21(3):227-34. [PMID: 10626030]

38. Kubzansky LD, Koenen KC, Spiro A 3rd, Vokonas PS, Sparrow D. Prospective study of posttraumatic stress disorder symptoms and coronary heart disease in the Normative Aging Study. Arch Gen Psychiatry. 2007;64(1):109-16. [PMID: 17199060]

39. Boscarino JA. Diseases among men 20 years after exposure to severe stress: Implications for clinical research and medical care. Psychosom Med. 1997;59(6):605-14.

[PMID: 9407579]

40. Aldwin CM, Yancura LA. Coping and health: A comparison of the stress and trauma literatures. In: Schnurr PP, Green BL, editors. Trauma and health: Physical health con- sequences of exposure to extreme stress. Washington (DC): American Psychological Association; 2004. p. 99-125.

41. Ford TG, Daniel E. Depression, trauma, and cardiovascular health. In: Schnurr PP, Green BL, editors. Trauma and health: Physical health consequences of exposure to extreme stress. Washington (DC): American Psychological Association; 2004. p. 73-97.

42. Dougall AL, Baum A. Psychoneuroimmunology and trauma. In: Schnurr PP, Green BL, editors. Trauma and health: Physical health consequences of exposure to extreme stress. Washington (DC): American Psychological Association; 2004. p. 129-55.

43. Friedman MJ, McEwen BS. Posttraumatic stress disorder, allostatic load, and medical illness. In: Schnurr PP, Green BL, editors. Trauma and health: Physical health consequences of exposure to extreme stress. Washington (DC): American Psychological Association; 2004. p. 157-88.

44. Schnurr PP, Green BL. Understanding relationships among trauma, posttraumatic stress disorder, and health outcomes. In: Schnurr PP, Green BL, editors. Trauma and health: Physical health consequences of exposure to extreme stress. Washington (DC): American Psychological Association; 2004. p. 247-75.

45. Zatzick DF, Jurkovich GJ, Gentilello L, Wisner D, Rivara FP. Posttraumatic stress, problem drinking, and functional outcomes after injury. Arch Surg. 2002;137(2):200-205. [PMID: 11822960]

46. Adams RE, Boscarino JA, Galea S. Alcohol use, mental health status and psychological well-being 2 years after the World Trade Center attacks in New York City. Am J Drug Alcohol Abuse. 2006;32(2):203-24. [PMID: 16595324$]$

47. Beckham JC, Kirby AC, Feldman ME, Hertzberg MA, Moore SD, Crawford AL, Davidson JR, Fairbank JA. Prevalence and correlates of heavy smoking in Vietnam veterans with chronic posttraumatic stress disorder. Addict Behav. 1997;22(5):637-47. [PMID: 9347066]

48. Boscarino JA. Posttraumatic stress disorder and mortality among U.S. Army veterans 30 years after military service. Ann Epidemiol. 2006;16(4):248-56. [PMID: 16099672]

49. Rheingold AA, Acierno R, Resnick HS. Trauma, posttraumatic stress disorder, and health risk behaviors. In: Schnurr PP, Green BL, editors. Trauma and health: Physical health consequences of exposure to extreme stress. Washington (DC): American Psychological Association; 2004. p. 217-44.

50. Sareen J, Cox BJ, Stein M, Afifi TO, Fleet C, Asmundson GJ. Physical and mental comorbidity, disability, and suicidal behavior associated with posttraumatic stress disorder in a large community sample. Psychosom Med. 2007;69(3): 242-48. [PMID: 17401056]

51. Taft CT, Stern AS, King LA, King DW. Modeling physical health and functional health status: The role of combat exposure, posttraumatic stress disorder, and personal 
resource attributes. J Trauma Stress. 1999;12(1):3-23. [PMID: 10027139]

52. Ford JD, Schnurr PP, Friedman MJ, Green BL, Adams G, Jex S. Posttraumatic stress disorder symptoms, physical health, and health care utilization 50 years after repeated exposure to a toxic gas. J Trauma Stress. 2004:17(3):185-94. [PMID: 15253090]

53. Vasterling JJ, Proctor SP, Amoroso P, Kane R, Gackstetter G, Ryan MA, Friedman MJ. The Neurocognition Deployment Health Study: A prospective cohort study of Army Soldiers. Mil Med. 2006;171(3):253-60. [PMID: 16602526]

54. Vasterling JJ, Proctor SP, Amoroso P, Kane R, Heeren T, White RF. Neuropsychological outcomes of army personnel following deployment to the Iraq war. JAMA. 2006; 296(5):519-29. [PMID: 16882958]

55. King DW, Leskin GA, King LA, Weathers FW. Confirmatory factor analysis of the Clinician-Administered PTSD Scale: Evidence for the dimensionality of posttraumatic stress disorder. Psychol Assess. 1998;10(2):90-96.

56. Ruggiero KJ, Del Ben K, Scotti JR, Rabalais AE. Psychometric properties of the PTSD Checklist-Civilian Version. J Trauma Stress. 2003;16(5):495-502. [PMID: 14584634]

57. Palmieri PA, Weathers FW, Difede J, King DW. Confirmatory factor analysis of the PTSD Checklist and the Clinician-Administered PTSD Scale in disaster workers exposed to the World Trade Center Ground Zero. J Abnorm Psychol. 2007;116(2):329-41. [PMID: 17516765]

58. Proctor SP, Heeren T, White RF, Wolfe J, Borgos MS, Davis JD, Pepper L, Clapp R, Sutker PB, Vasterling JJ, Ozonoff D. Health status of Persian Gulf War veterans: Self-reported symptoms, environmental exposures and the effect of stress. Int J Epidemiol. 1998;27(6):1000-1010. [PMID: 10024195]

59. Ware J Jr, Kosinski M, Keller SD. A 12-Item Short-Form Health Survey: Construction of scales and preliminary tests of reliability and validity. Med Care. 1996;34(3):220-33. [PMID: 8628042]

60. Ware JE, Kosinski M, Turner-Bowker DM, Gandek B. SF12v2: How to score Version 2 of the SF-12 Health Survey (with a supplement documenting Version 1). Lincoln (RI): QualityMetric Incorporated; 2002.
61. Lenert LA. The reliability and internal consistency of an internet-capable computer program for measuring utilities. Qual Life Res. 2000;9(7):811-17. [PMID: 11297023]

62. Salyers MP, Bosworth HB, Swanson JW, Lamb-Pagone J, Osher FC. Reliability and validity of the SF-12 health survey among people with severe mental illness. Med Care. 2000;38(11):1141-50. [PMID: 11078054]

63. Muthén LK, Muthén BO. Mplus (Version 4.1) [Computer software]. Los Angeles (CA): Muthén \& Muthén; 2006.

64. Cohen J. Statistical power analysis for the behavioral sciences. 2nd ed. Hillsdale (NJ): Lawrence Erlbaum Associates; 1988.

65. Muthén LK, Muthén BO. Mplus version 4 user’s guide. Los Angeles (CA): Muthén \& Muthén; 2006.

66. Tabachnick B, Fidell LS. Using multivariate statistics. 4th ed. Boston (MA): Allyn and Bacon; 2001.

67. Bentler PM. Comparative fit indexes in structural models. Psychol Bull. 1990;107(2):238-46. [PMID: 2320703]

68. Steiger JH. Structural model evaluation and modification: An interval estimation approach. Multivariate Behav Res. 1990;25(2):173-80.

69. Browne MW, Cudeck R. Alternative ways of assessing model fit. In: Bollen KA, Long JS, editors. Testing structural equation models. Newbury Park (CA): Sage; 1993. p. 136-62.

70. Hu LT, Bentler PM. Fit indices in covariance structure modeling: Sensitivity to underparameterized model misspecification. Psychol Methods. 1998;3(4):424-53.

71. Breslau N, Davis GC, Peterson EL, Schultz LR. A second look at comorbidity in victims of trauma: The posttraumatic stress disorder-major depression connection. Biol Psychiatry. 2000;48(9):902-9. [PMID: 11074228]

72. Sharkansky EJ, King DW, King LA, Wolfe J, Erickson DJ, Stokes LR. Coping with Gulf War combat stress: Mediating and moderating effects. J Abnorm Psychol. 2000;109(2): 188-97. [PMID: 10895556]

73. McEwen BS, Stellar E. Stress and the individual. Mechanisms leading to disease. Arch Intern Med. 1993;153(18): 2093-2101. [PMID: 8379800]

Submitted for publication May 31, 2007. Accepted in revised form October 16, 2007. 